\title{
Scalar Consequentialism the Right Way
}

Philosophical Studies 175, 3131-3144, 2018

Neil Sinhababu - neiladri@gmail.com - National University of Singapore

\section{Typesetting errors in the published version compressed the four paragraphs of the introductory section into one. This version has the more readable introduction that was intended.}

Rightness and wrongness come in degrees that vary on a continuous scale. After demonstrating this with examples, I'll consider how to develop a consequentialist theory that accounts for ordinary thought about right and wrong, and present problems that some deontological theories face in doing so.

Scalar properties can vary on a continuous scale. We often refer to them with gradable adjectives like "good", comparative forms like "better", and superlative forms like "best". Scalar properties differ from discrete properties, which don't vary on a continuous scale. We often refer to discrete properties with adjectives including "right", "wrong", "permissible", and "obligatory", for which such comparative and superlative forms are ungrammatical.

I'll argue that rightness is scalar. (The same holds for wrongness. For brevity, I'll frequently omit mention of wrongness.) "Righter" isn't a grammatical English expression, which might seem like evidence that rightness is discrete rather than scalar. In fact, "righter" expresses our moral thinking at least as well as "right". But we need not abandon unsuffixed "right". A variety of linguistic resources help us provide truth-conditions for claims including "right". This suggests new ways of developing scalar consequentialism, which was pioneered by Alastair Norcross (1997, 2006a, 2006b, 2008, ms).

Section 1 argues that we ordinarily judge the rightness of action to be a scalar property. Section 2 considers linguistic resources that scalar consequentialists can use to understand unsuffixed "right". Section 3 presents an advantage scalar consequentialism has over some agentcentered deontological theories in accounting for scalar rightness.

\section{Rightness and wrongness come in degrees}

Ordinary cases of action demonstrate that rightness and wrongness are scalar, as this section shows. Consider the following case: Betsy promised to see a documentary about Stalin's purges with her friend Daniel. It's time to go, but she doesn't feel up for anything so emotionally draining. So she texts Daniel to say that she isn't coming, puts her phone away, and plays video games while Daniel sits by himself at the movie. Daniel watches the movie unhappily, not only because of the grim events on the screen, but because Betsy broke her promise and didn't come. Their friendship suffers as a result.

We see that rightness and wrongness are scalar when we consider other things Betsy could have done. It was wrong to break her promise and play video games, but she could've done worse. She could've burglarized Daniel's house while he was at the movie. She could've run around on the street merrily assaulting people until someone forced her to stop. She even could have fulfilled her promise in an awful way, wearing a suicide bomb vest under her jacket and detonating it at the end of the movie to kill everyone in the theater. (For those who prefer more mundane possibilities: she could've stayed home without sending a message to let him know that she wouldn't be coming.) These actions are more wrong than simply breaking the promise and playing video games. The moral difference between the actions of keeping the promise and breaking it to play video games is much smaller than the difference between the actions of breaking the promise to play video games and killing a theater full of people. 
Action usually is like this. We rarely have only two options, one of which is right and one of which is wrong. We usually have a great number of other options, some of which are even more wrong and may involve wanton mayhem. Instead of giving money to the homeless or walking briskly past them, you could snatch the money they've already collected and run away. Instead of grading your students' exams on time or procrastinating, you could light the exams on fire and use them to burn down university buildings. Instead of refraining from action or pushing a fat man over a bridge to block a trolley that would otherwise run over five people, you could wait until the trolley runs over the five people and then push the fat man over the bridge.

Moral judgments apply to these terrible options whether or not agents actually consider them. If a liar doesn't even consider telling the truth, that doesn't make the lie any better or change the fact that telling the truth was the right thing to do. Likewise, blowing up the movie theater counts as a horribly wrong action even if Betsy never considers it. Nice people don't usually consider such terrible options in the ordinary course of moral deliberation, and they may feel discomfort if forced to consider them deeply. When considering them superficially, they may be amused at the absurdity of doing such things. But however we might or might not consider the options, they exist and have varying levels of rightness.

Our moral judgments concerning the whole range of actions available to an ordinary agent outstrip the expressive force of the unsuffixed terms "right" and "wrong". Ordinary people have a vast range of morally differing options, unlike the protagonists of Judith Jarvis Thomson (2008) and Frances Kamm's (2007) trolley problems, who typically have only two options: acting to affect the motions of an out-of-control trolley and doing nothing. This makes unsuffixed "right" and "wrong" useful for evaluating options in trolley cases. But dividing ordinary agents" many options into three categories (the right, the wrong, and the neither right nor wrong; or perhaps the obligatory, the forbidden, and the permissible) doesn't do justice to the full range of moral differences between them. Just as we need "better" in addition to "good" to describe the full range of moral differences between states of affairs, we need comparative terms to describe the full range of moral differences between actions in real-world cases.

For similar cases displaying the magnitude of differences specifically within the domain of right action, consider differing levels of supererogatory behavior. Common sense treats donating large percentages of one's income to highly cost-effective charities as supererogatory. If Toby donates $40 \%$ of his income to charity, he acts rightly and merits considerable praise. But if he gave up more personal comforts to donate $50 \%$ of his income instead, he'd deserve even more praise and esteem. While donating $40 \%$ is certainly praiseworthy and beyond the call of duty, donating $50 \%$ is even more praiseworthy and further beyond the call of duty. When we think about how little most people do, both options seem right, one more so than the other.

At some times, one might instead want to say that between Toby's option to donate $40 \%$ and his option to donate $50 \%$, donating $50 \%$ is the right thing to do and $40 \%$ isn't the right thing to do. This intuition suggests maximizing consequentialism, according to which only the option that produces the best outcome is right. But when we retreat from consideration of Toby's choice between these two options and consider his decision in light of how most similarly situated people act, it's easy to shift back into seeing Toby as acting rightly in donating $40 \%$, which accords better with scalar consequentialism. Why our judgments shift in this way is an interesting question which the linguistic theories discussed in the next section will help us answer.

In Betsy's case, the wrongness of breaking her promise to Daniel is far less than that of killing everyone in the theater with a bomb. When we compare peacefully watching the movie as she promised, breaking the promise for video games, and killing everyone in the theater, the moral difference between the first two options seems smaller than the moral difference between 
the latter two options. While the latter two are both wrong, the difference in their wrongness is vast. Things seem similar in the other cases I've mentioned. The size of the moral difference between two wrong actions will often seem much larger than the difference between the less wrong action and right action. Similarly, a hot summer day and a cold winter night are closer on the spectrum of heat and coldness than either is to the center of the sun or the surface of Pluto. Heat and coldness strike us as matters of degree, just as rightness and wrongness do.

Language that treats rightness and wrongness as a matter of degree lets us describe actions as they seem. In Betsy's case and many others, the difference between right and wrong actions seems much smaller than the difference between wrong and extremely wrong actions. Expressing the magnitude of this difference requires going beyond expressions like "right" and "wrong". Despite offending against English grammar, talk of how much "righter" and "wronger" various options are than others would express our thoughts nicely.

"Righter" and "wronger" may not please the ears of philosophers who demand fidelity to the English language. But when our language doesn't adequately express our thoughts, it's better to add expressions to our language than to abandon our thoughts. This is one reason why languages evolve over time. Speakers add new terms so they can express additional thoughts. The continuous moral distinctions we recognize between the many options available to ordinary agents show that we think about rightness as scalar. Whether with the neologism "righter", the short expression "more right", or more resonant expressions like "great deed", expressing our judgments of action requires language that can describe our options' varying degrees of rightness. The grammaticality of "more wrong" suggests that "wrong" is a gradable adjective, following Chris Kennedy's (2006) semantics. ${ }^{1}$ Croatian friends tell me that their language has single-word comparative and superlative expressions for "right". "Ispravno," "ispravnije", and "najispravnije" mean "right", "righter", and "rightest". Perhaps English subtly misleads us about our moral concepts by making their most concise expressions ungrammatical, while Croatian doesn't. ${ }^{2}$

Julia Driver (2012) argues against a scalar treatment of "right" by noting a colloquial way of doubling scalar terms. For example, to ask whether something is moderately hot or very hot, one can ask, "But is it hot hot?" (44). She allows that "wrong wrong" might be okay - perhaps as applied to murder to distinguish it from jaywalking. She regards "right right" as odd, and treats this as evidence that "right" doesn't admit of degrees. But I think there are cases in which "right right" might be used. Suppose two children fall off opposite sides of a boat into a cold and stormy sea. Both Leif and Inga realize that both children will die without help, and that only one life preserver is available. Leif throws the life preserver to one child. Inga jumps into the stormy sea to rescue the other. After both children are safely back in the boat, Leif might describe his act of throwing the life preserver as "right, but not right right" to provide proper contrast with Inga's heroic deed. This is a type of situation where he might use "more right" to describe her action. If this is correct, the linguistic phenomenon that Driver notes may merely be a contingent product of a world undersupplied with heroes.

Philosophical discussion of scalar rightness often concerns how stringent moral requirements are, for an important dialectical reason. Scalar consequentialists like Norcross and satisficing consequentialists like Michael Slote and Philip Pettit (1984) want to show that consequentialism doesn't require driving oneself into poverty to donate large proportions of one's

${ }^{1}$ I thank Robbie Williams and Mitchell Erlewine for help on this point.

${ }^{2}$ I thank Tomislav Janović and Matej Susnik for teaching me about this philosophically valuable feature of Croatian grammar. 
income to the global poor, as Peter Singer's (1972) famous arguments might suggest. But the true importance of scalar rightness comes from a more general fact that isn't internal to consequentialism: "right" and "wrong" by themselves fail to express a great deal of the character of moral evaluation, once we consider the full range of options that human agents have in ordinary situations.

Metaethical accounts of moral judgment accommodate scalar rightness, as they all analyze rightness in terms of scalar parameters. On T. M. Scanlon's (1998) reasons-first cognitivist view, judging an action to be right is believing that there are objective reasons of a certain kind for doing it. As reasons vary continuously in weight, this view treats judgments about differing degrees of rightness as beliefs about more or less weighty moral reasons for action. On Allan Gibbard's (1990) noncognitivist view, judging an action to be right is having a kind of motivationally potent pro-attitude towards it. Since the motivational force of these pro-attitudes varies continuously, this view treats judgments about differing degrees of rightness as more or less motivationally powerful pro-attitudes of this kind. On David Brink's (1989) externalist view, judging an action to be right is believing that it has the natural property which "right" rigidly designates. As the magnitudes of many natural properties vary continuously, this view treats judgments about differing degrees of rightness as beliefs ascribing different magnitudes to this natural property. On my (2017) experientialist version of cognitivism, judging one's action to be right is believing that a feeling like pride is an accurate perceptual representation of its objective nature. Since one can believe that more or less pride would accurately represent one's action, this view treats judgments about different degrees of rightness as beliefs that feeling more or less pride would be accurate.

Action is guided better by scalar properties than by discrete properties. One source of worry about scalar guidance is that action is discrete to the point of being binary. For any action, one either does it or doesn't, with no in-between values. Does this mean that guidance has to be discrete or even binary? ${ }^{3} \mathrm{No}^{-}$in fact, scalar guidance is often better. Suppose Aaron wants to go to the airport, and he asks Mohua whether he should take the subway, take a cab, walk, or steal a car. Mohua tells him that taking the subway is the best option, that taking a cab is also a fine option, that walking is a bad option, and that stealing a car is a terrible option. This detailed guidance has a scalar structure. Taking a cab would go slightly against Mohua's guidance, but not as much as stealing a car. By contrast, binary guidance that matched the structure of action couldn't be so detailed. Mohua would have to group the options into two categories, at least one of which would lump together options that better guidance would distinguish. If she had to guide Aaron to exactly one option, fully matching the binary structure of action, she'd have to treat taking a cab like stealing a car.

Internalist views on which moral judgments have intrinsic motivational force can incorporate scalar guidance, as motivation is scalar and not discrete. Scalar rightness judgments can then produce differing levels of motivation concerning our options. Differing levels of wrongness in lazily violating her promise, violating it to commit crimes, and keeping it but committing mass murder might weigh differently on Betsy as she decides what to do. Even if judging it wrong to break her promise doesn't generate enough motivation to make her keep it, judging it very wrong to burglarize Daniel's house or murder people might motivate her not to do those terrible things.

I've argued that the reason for understanding rightness as scalar comes directly from the different levels of rightness we naturally recognize in ordinary agents' options. We have this

${ }^{3}$ I thank Derek Baker for this explicit formulation of the problem. 
reason regardless of which normative ethical theory we might accept, unless we accept the implausible view that all of Betsy's wrong options are equally wrong. Discrete terms like "right" are insufficient for drawing the continuous range of distinctions that we recognize between the options. While "right" applies to some options, there's a great deal more to be said about their rightness than unsuffixed "right" can express. This is why ethical theories that treat rightness as a matter of degree suit ordinary moral thinking better than theories that treat it as discrete.

Norcross (2006a) suggests a version of scalar consequentialism which shares some features with the view I've advanced here:

Utilitarianism should not be seen as giving an account of right action, in the sense of an action demanded by morality, but only as giving an account of what states of affairs are good and which actions are better than which other possible alternatives and by how much. The fundamental moral fact about an action is how good it is relative to other available alternatives. Once a range of options has been evaluated in terms of goodness, all the morally relevant facts about those options have been discovered. There is no further fact of the form ' $\mathrm{x}$ is right', ' $\mathrm{x}$ is to-be-done', or ' $\mathrm{x}$ is demanded by morality.' (228)

Norcross' work inspires the scalar consequentialist view that this paper defends. Unfortunately, the way he develops his argument unnecessarily gives rise to objections. For example, his focus on a utilitarian persuader's preferences in the case of two people giving to charity invites Lang's (2013) objection that a persuader's preference between options doesn't reveal the options' moral value. Lang is right about this, which is why I don't invoke a persuader's preferences here. The best case for scalar rightness is made simply by appealing to the varying degrees of rightness across our total set of options in most ordinary cases of action.

Further unclarities in Norcross' view have given rise to objections from Brian McElwee (2010) and Rob Lawlor (2009), both of whom quote the above passage in its entirety before responding to it. The next two sections address issues they raise. I won't focus on interpreting Norcross' remarks or keeping score in his debate with McElwee and Lawlor. Instead, I'll suggest ways of developing scalar consequentialism that avoid the problems his critics point out. Section 2 addresses McElwee's concern that scalar consequentialism requires rejecting right and wrong altogether, suggesting ways of accommodating right and wrong within the scalar consequentialist framework. Section 3 addresses Lawlor's objection to arguments from scalar goodness to scalar rightness, proposing a new and more ambitious direction of argument.

\section{Unsuffixed "right" and "wrong"}

This section addresses McElwee's concern that scalar consequentialism requires denying that anything is right or wrong. After agreeing with Norcross that maximizing consequentialism fails to account for how we think of right and wrong, McElwee cites the above passage from Norcross and writes, "Norcross goes to the opposite extreme, in denying that there are any moral demands whatsoever; on his view, nothing is morally wrong. This is at least as large a departure from our considered moral judgement" (398). Rejecting right and wrong altogether would indeed be an extreme and unappealing position. Fortunately, better options are available.

One can agree with Norcross that there is no "further fact" about an action's being right beyond the facts about the goodness of the various outcomes, and still say it's a fact that the action is right. Instead of eliminating rightness, we can reduce it to the goodness of the consequences that right action generates. This reductive realist version of scalar consequentialism permits us to describe facts and speak truly when we say that actions are right. That a building is 
tall isn't a further fact beyond its height. In the same sense, that an action is right isn't a further fact beyond the goodness of its consequences. In understanding how to use words like "right", we might need to consider more facts which a full linguistic theory of the term "right" would need to account for, just as a full linguistic theory of "tall" might have to consider facts beyond the object's height. But on a conception of facthood coarse-grained enough that a building's being tall isn't a further fact beyond its height, these facts will be the same.

One challenge for understanding right action in terms of goodness is to distinguish levels of goodness that aren't sufficient for right action from those that are. Maximizing consequentialists take an extreme approach here, treating only the maximizing option (or options in case of a tie) as right. Unfortunately, doing so prevents them from accommodating degrees of rightness and makes morality seem very demanding. But this extreme approach at least sets a clear cutoff above which one has created enough goodness for one's action to be right. Setting the cutoff for rightness anywhere else might seem arbitrary. How can scalar consequentialists set a cutoff above which the good consequences of action are sufficient for rightness?

To determine which level of goodness is sufficient for rightness, scalar consequentialists can use the same mechanisms that distinguish temperatures sufficient for a day's being hot from temperatures that aren't, and heights sufficient for a building's being tall from heights that aren't. In whatever sense it's true that there's nothing more to being tall than height, and nothing more to being hot than temperature, there's nothing more to an action's being right than the goodness of consequences. These linguistic resources have been put to good use in epistemology by contextualists, subject-sensitive invariantists, assessor-relativists, and contrastivists. On these various approaches, the cutoff between consequences good enough for rightness and consequences insufficiently good for rightness will depend on features of the various options themselves, options that have arisen in the context of making the rightness-attribution, options that have arisen in the context of assessing the rightness-attribution, or options with which we're contrasting the action.

To see how the phenomena under discussion call for the application of these linguistic resources, let's again consider Toby, who is giving 40\% of his income to charity. Commonsense morality tells us that this is the right thing to do. But if he were choosing between giving $40 \%$ and giving $50 \%$, with the additional $10 \%$ coming from giving up personal comforts of no significant moral value, there's at least some temptation to say that giving $50 \%$ is the unique morally right choice.

These are the same phenomena that we encounter in discussing whether a building is tall. In a small town where no other building is over 3 stories, a 7-story building is accurately described as tall. But a 7-story building in midtown Manhattan isn't accurately described as tall. The rightness of donating 40\% towers over the rightness of most people's charitable activity, just as the 7-story building towers over the other buildings in the small town. But it also falls short of the rightness of giving 50\%, just as the 7-story building falls short of the height of Manhattan skyscrapers.

Similar phenomena in epistemology have attracted a great deal of philosophical attention. Many attributions of knowledge, like the statement that George knows he has hands, are easily defended in ordinary contexts. George can rule out the possibility that he doesn't have hands by visually and kinesthetically sensing that he has hands. But these knowledge attributions are hard to defend against skeptics who ask how George would rule out the possibility that he's a handless brain in a vat, with deceptive visual and kinesthetic experience fed to him by a computer program. David Lewis proposes a contextualist explanation in "Elusive Knowledge" (1996): in ordinary contexts, the range of possibilities that one must rule out in order to have 
knowledge is relatively small. So George's evidence easily passes the ordinary threshold for knowledge, just as the seven-story building in the small town easily passes the threshold for being tall, and just as donating 40\% passes the ordinary threshold for doing right. But things change when we attend to a larger range of possibilities, including skeptical scenarios that our evidence can't rule out. Then George's evidence falls short of knowledge, just as the seven-story building in midtown Manhattan falls short of tallness, and just as donating 40\% falls short of the rightness of donating $50 \%$.

There is much debate in epistemology about whether contextualist linguistic mechanisms or those of some other theory best explain phenomena of this kind. Participants in this debate include Lewis' fellow contextualist Keith DeRose (2009), interest-relative invariantist Jason Stanley (2006), assessor-relativist John MacFarlane (2014), and contrastivist Jonathan Schaffer (2004). As the question of which theory is best for understanding right action is too subtle and complex to settle here, I invite philosophers with expertise in these approaches to help us answer it. There are a wide variety of similar terms across moral theory, including "good" itself. How much goodness must a state of affairs have in order to be called "good"? Here again we encounter the same phenomena that appear with "tall" and "hot". We have many tools for handling these phenomena, and the only question is which tool or combination of tools will handle each phenomenon best.

Norcross (2006b) considers contextualism about "right" and "good". His remarks about the metaphysical position suggested by contextualism are difficult to interpret, and in any case seem to unduly narrow scalar consequentialists' options. So rather than treat his remarks as commitments of the position, I've laid out a range of theoretical options for understanding these terms, from which scalar consequentialists can choose as they please.

Some might ask why we should bother to retain "right", if it merely applies to action with consequences above a salient level of goodness. We should first recognize that it's okay to have multiple terms for the same thing at different levels of fundamentality. It's fine to keep using "water" after learning that water is nothing more than $\mathrm{H}_{2} \mathrm{O}$. Similarly, it's fine to use "right" after learning that rightness is causing some salient high level of good consequences.

Using "right" and "wrong" to regulate action may also have practical benefits. People may have desires with concepts like right and wrong in their content, desiring to do the right thing and not the wrong thing in a de dicto sense. While Michael Smith (1994) calls acting on such de dicto moral desires "moral fetishism", Vanessa Carbonell (2013) seems right to consider it a legitimate form of moral motivation. Statements including "right" and "wrong" may then speak more directly to people's desires, in addition to being true. The practical spirit of consequentialism counsels against casting "right" away when it can work for us.

\section{Continuous parameters and scalar rightness}

This section addresses Rob Lawlor's objection that scalar goodness doesn't entail scalar rightness, suggesting a better and more ambitious direction of argument for scalar consequentialists. Here is how Lawlor represents Norcross' argument before responding to it:

First, he asserts that, according to consequentialism, 'the property of an act that makes it right or wrong - how much good it produces relative to available alternatives - is naturally thought of as a matter of degree'. He then asks, 'Why, then, is rightness and wrongness not a matter of degree?' (101)

As Lawlor argues, scalar goodness of consequences doesn't entail scalar rightness of the actions 
that cause them, even if the goodness explains the rightness. To demonstrate this, Lawlor provides the example of a long jump competition. Distance is scalar, and the competitors' jumps can have more or less distance. These distances determine who the winner is. But winning is discrete. One isn't more the winner if one's jump exceeded that of one's nearest rival by a longer distance rather than a shorter distance. There's no way to be more or less the winner, apart from simply winning or not winning. Lawlor's case shows that the continuous nature of a more fundamental property doesn't entail that the property it explains is also continuous.

Put more generally, Lawlor's point is that continuous values can easily explain discrete values. All one needs is a way to set a cutoff in the continuous values. In Lawlor's example, we'd put the cutoff for winning anywhere between the winner's jump and the second-place finisher's jump. Then the discrete values can be understood in terms of being above or below the cutoff. Norcross himself seems to appreciate this, as he suggests drawing cutoffs for rightness wherever it would be utility-maximizing to do so, with different cutoffs applying in different societies.

What's difficult is using discrete values to explain a full range of continuous values. Discrete values won't have enough variation to explain all the continuous values. The argument Lawlor attributes to Norcross fails because the continuous can easily explain the discrete. But problems with using the discrete to explain the continuous let scalar consequentialists produce a better and more ambitious argument that runs the opposite way.

Scalar consequentialists should first demonstrate that rightness is a matter of degree by considering our ordinary evaluations of the many options ordinary agents have. The point of discussing Betsy, Toby, and other ordinary people who have many options with varying degrees of rightness was to demonstrate this: rightness is a matter of degree, and treating it as discrete doesn't do justice to how we evaluate our full range of options. Scalar consequentialists can then challenge opposing moral theorists to explain how rightness can be a matter of degree. David Hume (1739/2003) makes such an argument against rationalists who think rightness and wrongness consist in agreement and disagreement with moral truth: "that this agreement or disagreement, not admitting of degrees, all virtues and vices would of course be equal" (3.1.1). ${ }^{4}$

Many moral theories allow for scalar rightness, as many of them include continuous parameters among the right-making features of action. ${ }^{5}$ This allows them to explain scalar rightness. If a feature that makes an action right varies continuously, more or less of that feature can explain the action's degree of rightness. Within this picture, discrete rightness could still be preserved by setting a cutoff in the continuous parameter, as Lawlor points out. The trouble with doing so, apart from highly specific applications like accommodating unsuffixed "right", is that it doesn't fit well with our ordinary concept of rightness. Rightness seems to be scalar, as we see differences in rightness and wrongness between the many things Betsy and Toby could do. This is the problem with following Lawlor's example of the long jump competition and using continuous goodness to explain discrete rightness.

Moral theories which don't include continuous parameters among the right-making features of action will have difficulty accommodating scalar rightness. Examples include some archenemies of consequentialism: Immanuel Kant's (1785/2011) Formula of Universal Law and Formula of Humanity, and versions of agent-centered deontology that evaluate actions in terms of the act-types they instantiate. ${ }^{6}$ Scalar consequentialists who have established the need for

${ }^{4}$ I thank John Tilley for making me aware of Hume's view.

${ }^{5}$ I thank Peter Murphy for putting the point this way.

${ }^{6}$ I thank Samuel Kahn for telling me about parts of Kant's philosophy outside the Groundwork that might support finer-grained distinctions than this formula does. 
scalar rightness by considering ordinary cases can argue that these theories fail to account for the degrees of rightness we comprehend in ordinary moral thinking. I'll show why these theories have difficulty accommodating scalar rightness, and then show why it's easy for consequentialists.

The Formula of Universal Law is particularly bad for explaining scalar rightness, as it uses the discrete parameter of not entailing a contradiction to explain the rightness of action. The formula is: "act only in accordance with that maxim through which you can at the same time will that it become a universal law" (4:421). The reason one might not be able to will a maxim as universal law is because it would entail a contradiction. That the maxim entails a contradiction when willed as universal law is what makes it wrong. But whether something entails a contradiction doesn't come in degrees. On standard theories of logic and any theory Kant might've accepted, things either entail contradictions or they don't, without intermediate degrees of entailing contradictions. This is why continuously varying degrees of scalar rightness and wrongness can't be explained by the Formula of Universal Law.

As stated, Kant's Formula of Humanity has a similar problem. This formula is: "So act that you use humanity, whether in your own person or in the person of any other, always at the same time as an end, never merely as a means" (4:429). Whether one uses someone merely as a means is a discrete matter, merely because of "merely". If one treats another person even slightly as an end, one isn't using that person merely as a means, so the action isn't wrong. So as stated, the Formula of Humanity doesn't allow scalar rightness. This problem can be avoided by revising it so that an action is right to the extent that it treats others as ends, and wrong to the extent that it treats others as means. Making some concessions to the rational ends of the person one manipulates would then be less wrong than manipulating the person without concessions.

Deontological theories that evaluate actions in terms of the act-types they instantiate will have difficulty accounting for continuous values of rightness, as act-types are instantiated discretely and not in degrees. Heidi Hurd (1999) discusses such theories in depth, while Ron Aboodi, Adi Borer, and David Enoch (2008), Ralph Wedgwood (2011), and Patrick Hawley (2008) provide various defenses. Such deontologists might account for the wrongness of an action in terms of its being an instance of theft. But not all thefts are equally wrong. It's more wrong to steal a child's most beloved stuffed animal than to steal one that the child cares little about, and more wrong to steal food from the starving than to steal food from those who have plenty of other food to eat. The ways these thefts differ in wrongness can't be explained by differing degrees to which they instantiate their wrong-making property: being thefts. They all instantiate the property of being thefts discretely. That being a theft is a discrete property prevents it from explaining the differing wrongness of various thefts.

Can deontologists who invoke act-types invoke a theoretically primitive level of rightness for each possible action that an agent might perform, accounting for scalar rightness without continuous parameters in their fundamental moral theory? Only at the cost of accepting an endless proliferation of fundamental moral facts, one for the rightness of each possible action. Such a moral theory would be radically complex and disunified. Moral particularists like Jonathan Dancy (1999) might tolerate such disunity, having already accepted radical disunity in moral theory. But those who haven't given up on theoretical unity should recognize the cost of doing so.

Sufficiently sophisticated versions of these deontological theories developed by sufficiently clever deontologists might incorporate continuous parameters, explaining how different actions have different degress of rightness. And perhaps deontologists can bite the bullet and accept a revisionary moral theory that treats rightness as discrete even though this isn't how an ordinary agent's full range of options seem. Since their theoretical creativity might lead them in directions 
I can't predict, I'll conclude my discussion of possible deontological solutions here.

Consequentialists are in good position to explain scalar rightness, since they invoke continuous parameters in the accounts of goodness they use to explain rightness. A little more pleasure (or desire-satisfaction or whatever is on the objective-list theorist's objective list) makes a state of affairs a little better, and a lot more makes it a lot better. In terms of how Betsy's actions affect aggregate pleasure, there's a smaller difference between peacefully keeping her promise and breaking it to play video games than between breaking it to play video games and keeping it but blowing up a theater full of people. Differences in total goodness between the aggregate consequences of various wrong actions explain why some are more wrong than others.

Goodness intuitively comes in degrees, so scalar consequentialism accords with intuitions about discreteness and continuity all the way up. States of affairs can be a little better, a lot better, a little worse, or a lot worse. There is little reason to regard the goodness of states of affairs as a discrete matter that doesn't admit of continuous values. So scalar consequentialism proceeds smoothly from an intuitive account of scalar goodness to an intuitive account of scalar rightness.

Perhaps recognizing this fact, early consequentialists formulated their theories in scalar terms. Consider John Stuart Mill (1987): "The creed which accepts as the foundation of morals, Utility, or the Greatest Happiness Principle, holds that actions are right in proportion as they tend to promote happiness, wrong as they tend to produce the reverse of happiness" (14). As noted by Norcross (2006a), Mill here treats rightness as a matter of degree, proportional to the tendency of the action to promote happiness. Francis Hutcheson (2008) similarly proposes scalar evaluation of actions in terms of how much happiness they create:

In comparing the moral Qualitys of Actions, in order to regulate our Election among various Actions propos'd, or to find which of them has the greatest moral Excellency, we are led by our moral Sense of Virtue to judge thus; that in equal Degrees of Happiness, expected to proceed from the Action, the Virtue is in proportion to the Number of Persons to whom the Happiness shall extend... (163)

Much of Hutcheson's language differs from contemporary usage. For instance, he calls the moral quality of actions "Virtue" instead of rightness. But he uses the same phrase as Mill - "in proportion to" - to specify the degree to which this quality is instantiated.

The illustrious ancestry of scalar consequentialism makes one wonder why so many $20^{\text {th }}$ century consequentialists abandoned it, leaving Norcross to reclaim it in the $21^{\text {st }}$. Perhaps the grammar of English "right" misled consequentialists into thinking rightness had to be discrete. Perhaps consequentialists paid too much attention to simplified cases like trolley problems with too few options to motivate scalar consequentialism. Or perhaps the prestige of Kantian moral theory made them feel that they had to accommodate the discrete account of rightness to which the Formula of Universal Law is deeply committed. Whichever mistake they made, I hope Norcross' arguments and mine help them fix it.

Recognizing rightness as scalar may make life easier for moral theorists who don't have allegiance to either consequentialism or deontology, as they frequently invoke continuous parameters among the right-making features of action. For example, virtue ethicists like Rosalind Hursthouse (1999) who explain the rightness of action in terms of whether it expresses virtuous character use continuous parameters to explain rightness. People and their character traits can be more or less virtuous and vicious, just as states of affairs can be better or worse. So virtue ethicists also need a way to set cutoffs for unsuffixed "right". They can follow the same strategy I've suggested for consequentialists, using scalar virtue to explain scalar rightness, and then applying 
contextualism or some similarly cutoff-making linguistic theory. They need not strain themselves to incorporate discrete rightness deeper into the structure of virtue ethics.

Scalar evaluation may be appropriate for nonmoral norms as well. McElwee (2017) argues that supererogation appears in normative domains including prudence, etiquette, and epistemic normativity. If both supererogation and forbiddenness come in degrees in these domains, with fine distinctions between a large range of options, the normative properties involved will be scalar.

Moral rightness, in particular, appears to be scalar when we evaluate the full range of options available to ordinary agents. Recognizing this helps everyone develop better theories of right action, and shows scalar consequentialists how to develop their theory the right way. ${ }^{7}$

${ }^{7}$ For helpful feedback on this paper, I thank audiences at the University of Waikato, Massey University, Colorado State University, the University of Akron, Cleveland State University, the University of North Carolina at Asheville, Indiana University-Purdue University Indianapolis, the University of Surrey, and the University of Oslo. 


\section{Bibliography}

Aboodi, Ron; Borer, Adi; \& Enoch, David (2008). Deontology, individualism, and uncertainty, a reply to Jackson and Smith. Fournal of Philosophy 105 (5):259-272.

Brink, David Owen (1989). Moral Realism and the Foundations of Ethics. Cambridge University Press.

Carbonell, Vanessa (2013). De dicto desires and morality as fetish. Philosophical Studies 163 (2):459477.

Dancy, Jonathan (1999). Defending particularism. Metaphilosophy 30 (1\&2):25-32.

DeRose, Keith (2009). The Case for Contextualism: Knowledge, Skepticism, and Context, Volume 1. Oxford University Press UK.

Driver, Julia (2012). Consequentialism. Routledge.

Gibbard, Allan (1990). Wise Choices, Apt Feelings: A Theory of Normative Judgment. Harvard University Press.

Hawley, Patrick (2008). Moral absolutism defended. Fournal of Philosophy 105 (5):273-275.

Hurd, Heidi M. (1999). Moral Combat. Cambridge University Press.

Hume, David (2003). A Treatise of Human Nature. Project Gutenberg E-Text.

Hursthouse, Rosalind (1999). On Virtue Ethics. Oxford University Press.

Hutcheson, Francis (2008). An Inquiry Into the Original of Our Ideas of Beauty and Virtue: In Two Treatises. Liberty Fund.

Kamm, F. M. (2007). Intricate Ethics: Rights, Responsibilities, and Permissible Harm. Oxford University Press.

Kant, Immanuel (2011). Groundwork of the Metaphysics of Morals: A German-English Edition. Cambridge University Press.

Kennedy, Chris (2006). Vagueness and grammar: the semantics of relative and absolute gradable adjectives. Linguistics and Philosophy

Lang, Gerald (2013). Should utilitarianism be scalar? Utilitas 25 (1):80-95.

Lawlor, Rob (2009). The rejection of scalar consequentialism. Utilitas 21 (1):100-116.

Lewis, David (1996). Elusive knowledge. Australasian fournal of Philosophy 74 (4):549-567.

MacFarlane, John (2014). Assessment Sensitivity: Relative Truth and its Applications. Oxford University Press.

McElwee, Brian (2010). The rights and wrongs of consequentialism. Philosophical Studies 151:393412.

Mill, John Stuart (1987). Utilitarianism and Other Essays. Penguin Books.

Norcross, Alastair (1997). Good and bad actions. Philosophical Review 106 (1):1-34.

Norcross, Alastair (2005). Contextualism for consequentialists. Acta Analytica 20 (2):80-90.

Norcross, Alastair (2006a). The scalar approach to utilitarianism. In Henry West (ed.), The Blackwell Guide to Mill's Utilitarianism. Wiley-Blackwell, 217-32. 
Norcross, Alastair (2006b). Reasons without demands: rethinking rightness. In James Lawrence Dreier (ed.), Contemporary Debates in Moral Theory. Blackwell, 6-38.

Norcross, Alastair (ms). Morality by Degrees: Reasons Without Demands.

Scanlon, Thomas (1998). What We Owe to Each Other. Belknap Press of Harvard University Press.

Schaffer, Jonathan (2004). From contextualism to contrastivism. Philosophical Studies 119 (1-2):73104.

Singer, Peter (1972). Famine, affluence, and morality. Philosophy and Public Affairs 1 (3):229-243.

Sinhababu, Neil (2017). Humean Nature. Oxford University Press.

Slote, Michael \& Pettit, Philip (1984). Satisficing consequentialism. Aristotelian Society Supplementary Volume 58 (1):139-176.

Smith, Michael (1994). The Moral Problem. Blackwell.

Stanley, Jason (2006). Knowledge and Practical Interests. Oxford University Press.

Thomson, Judith Jarvis (2008). Turning the trolley. Philosophy and Public Affairs 36 (4):359-374.

Wedgwood, Ralph (2011). Defending double effect. Ratio 24 (4):384-401. 